\title{
Editorial
}

\section{Funding and facilities in museums and art galleries}

The 32 papers presented at the 1995 EVA meeting are summarised below by Dr. James Hemsley, the chairman of the meeting, as an introduction to the full set available from Brameur Ltd., Clarke House, 2 King's Rd., Fleet, Hants GU13 9AD, England. In this issue of IS\&U, we publish 12 papers selected from the meeting.

There is much fuss and controversy about whether the public should pay when entering a museum or art gallery. Libraries have to consider similar alternatives. These organisations are wondering whether their budgets are adequate to dabble with devices designed to find or present collection items with the aid of electronics, and to what degree such dabbling might enhance their services. The idea that visitors unable to pay should be refused entry is strongly resisted. Museums and Galleries may be forced to take an unseemly interest in other ways of raising money. Many organisations become involved in minor marketing efforts - for instance on the way out, a visitor may be tempted to enter a shop containing goods connected or unconnected with their visit.

But the ideas that professionals consider "trade" to be unseemly and marketing unrespectable are dying concepts. This attitude was once prevalent, hence the remark made by a character in one of Marlowe's plays about "men of judgement framing their means of traffic from vulgar trade".

The application of telecommunication networks - now a frequent requirement may introduce both political and funding problems. The Remote Access to Museums (RAMA) project - a major effort to interconnect 20 sites, funded under the CEC RACE programme, was discussed by Delouis at the 1993 EVA meeting [1]. A market study was carried out under the auspices of the French and German telecom authorities for setting up a wideband network.

The network did not materialise and CEC funding ceased, forcing RAMA to form a self-funded interest group and consider here-and-now narrowband Internet using the TCP/IP protocol $[2,3]$. The PTTs have responded very slowly to the CEC's insistence that they should form a unified network. As supporters of the OSI protocol, the CEC take a jaundiced view of the success of the Internet/TCP/IP invasion of their heartland [4].

Several different organisations are concerned with the interests of museums. In Europe a number of ESPRIT and IMPACT supported projects are running. There 
are the Getty Conservation Institute and Archives and Museum Informatics in the United States, in France there is the National Museums Archive, and there are similar organisations in other countries.

In the UK, organisations interested in museums include the Department of National Heritage (expecting a doubling of its $£ 200 \mathrm{M}$ budget from the National Lottery) the Museum Documentation Association, the Electronic imaging and Visual Arts (EVA) annual event, and the International Visual Arts Information Network (IVAIN). As an outsider, I had imagined that museums would be daunted by a shortage of funds, telecoms politics, and their boring public image. However, this is not the case.

The EVA papers show that museums and galleries are thriving and are adopting electronic aids with enthusiasm; they are no longer boring. There is no evidence to support the idea that they still consider that commerce is vulgar. Often an outcome of their work with computers includes a commercially available end product. For instance, two CD-ROMs covering parts of the Louvre collection sell at around Ffr 400 and Attica markets a CD-ROM on behalf of the Liverpool Tate Gallery. There are many other examples.

Technology is often expensive - the budget for the Videomuseum at the Pompidou Centre is five million francs. But the 1995 EVA papers show that many museums are able to find the money in order to use state-of-the-art devices. Setting up a server on the World Wide Web has become almost commonplace as Jonathan Bowen shows in this issue. He provides some statistics as evidence of the popularity of museum pages. He does not mention the problem of data rate which makes the viewing of quality images a laborious business. I recently attempted to view a picture from the Vatican Library using a university's wideband link to the network. Its wide bandwidth was of little benefit because, as usual, the bit rate was limited by the slowest link in the interconnection chain. In this case I was unable to wait while the picture was laboriously scanned out.

Iwainsky and Schulze describe 3D modelling techniques as a means of generating images of complete objects reconstructed from fragmentary data. A similar exercise is periodically demonstrated to visitors to the Jorvik Viking Centre at York. Using 3D computer graphics the image of a skull of a Viking fisherman is overlaid with facial features believed to closely represent the appearance of the living original.

Stanke and Paul pursue the idea further, describing sophisticated image processing methods including the reconstruction of the amplitude variations within the sound tracks of Edison cylinder negatives enabling the original sounds to be heard.

The EVA papers published in this journal from 1993 onwards show that museums have rapidly caught up and are now applying computer processing and multimedia techniques which are as up to date as in any other field.

\section{References}

[1] Delouis, Dominique: Telecommunications in museums, Information Services \& Use 13, pp. 335346, 1993.

[2] Cisneros, Guillermo and A.L. Delclaux: RAMA - Remote Access to Museum Archives, Information Services \& Use 14, pp. 171-181, 1994. 
[3] Cisneros, Guillermo: Personal communication, September 1995.

[4] Cawkell, A.E.: Videoconferencing, the information superhighway and the second défi Américain, Information Services \& Use 15, pp. 73-74, 1995.

A.E. Cawkell 